\title{
Aktivite tanımlama için en etkin vücut bölgelerinin belirlenmesi
}

\author{
Gökmen AŞÇIOĞLU, Yavuz ŞENOL* \\ Dokuz Eylül Üniversitesi, Mühendislik Fakültesi, Elektrik-Elektronik Mühendisliği Bölümü, Tınaztepe \\ Yerleşkesi, Buca, İzmir \\ Gelis Tarihi (Recived Date): 20.09.2018 \\ Kabul Tarihi (Accepted Date): 21.10.2018
}

\section{Özet}

Günlük aktivitelerin izlenmesi ve gerçekleştirilen yaşam aktivitelerinden geri bildirim sağlanması birçok hastalığ önleyebilir ve bireylerin yaşam kalitesini yükseltir. Gerçekleştirilen akademik çalışmalarda genellikle gögüis üzerine yerleştirilen tek bir sensörden elde edilen verilerin çeşitli kompleks algoritmalarla kullanılması sonucu aktivite tanımlaması yapıldı ̆̆ de ğerlendirilmiştir. Bu çalışmada ise aktivite tanımlama için en efektif vücut bölgeleri belirlenmiştir. Bu amaçla, toplamda dört ivme sensörü gögüis, omuz, bacak ve kol bölgelerine yerleştirilmiştir. Yürüme, koşma, zıplama ve oturma-kalkma aktiviteleri süresince veriler topland. Tekli ve çoklu sensör verileri ile kullanılmasının aktivite tanımlama için yapay sinir ağları performansına etkisi incelenmiştir. Sonuçlar etkin bölgelerde çoklu sayıda sensör kullanmanın performansa daha olumlu yansıdığını ortaya çıkarmıştır.

Anahtar kelimeler: Günlük aktiviteler, sınıflandırma, yapay sinir ağları, ivme sensörü.

\section{Determination of the most effective human body regions for activity recognition}

\begin{abstract}
Monitoring daily activities and providing feedback from life activities performed can prevent many diseases and improve the quality of life of individuals. In the academic studies carried out, it was evaluated that the data obtained from a single sensor placed on the chest was used to define the resultant activity using various complex algorithms. In this study, the most effective body regions were identified for activity identification.
\end{abstract}

\footnotetext{
Gökmen AŞÇIOĞLU, gokmen.ascioglu@ ogr.deu.edu.tr, https://orcid.org/0000-0003-4329-0776

* Yavuz ŞENOL, yavuz.senol@deu.edu.tr, https://orcid.org/0000-0002-3686-5597
} 
For this purpose, total of four accelerometers were placed in the chest, shoulder, limb and arm regions. Data sets were collected for different activities including walking, running, jumping, and sit-to-stand. The performances of artificial neural networks were examined using single or multi-sensor data sets for activity recognition. The results show that using multi-sensor in effective parts has more positive impact on neural network performance.

Keywords: Daily activities, classification, artificial neural networks, accelerometer.

\section{Giriș}

Yetersiz fiziksel aktivite, global ölüm sebepleri sıralamasında en riskli faktörler arasında yer almaktadır. Dünya Sağlık Örgütü istatistiklerine göre her dört yetişkinden birinin aktif yaşam tarzını sürdürmediği ve global çapta her yıl ortalama 3.2 milyon bireyin yetersiz harekete bağlı olarak hayatını kaybettiği belirtilmiştir [1]. Ayrıca, bireylerin çeşitli sağlık problemleri ile karşılaşabilme ihtimalinin arttığı birçok çalışma ile kanıtlanmıştır [2-4]. En sık rastlanan sağlık problemlerinin başında kardiyovasküler hastalıklar, diyabet, kolon kanseri ve depresyon gelmektedir.

Çeşitli teknolojik gelişmeler, bireylerin günlük aktivite yoğunluğunu azaltmak ve hayatı kolaylaştırmak için avantaj olarak görünmesine karşın, hareketsiz bireylerin sayısını arttırmakta ve sağlığı olumsuz etkilemektedir. Yürüme, bisiklet sürmek veya spor yapmak gibi düzenli aktiviteler ise sağlık açısından önemli yararlara sahiptir. Her hafta ortalama 150 dakika fiziksel aktivite gerçekleștiren bireylerin diyabet riski \%27, gögüis ve kolon kanseri riski ise \%23 civarında azalmaktadır. Ayrıca, yeterli seviyelerde gerçekleştirilen günlük aktiviteler kalça ve omur kırılmasını azalmakta ve kilo kontrolünde de yardımcı olmaktadır [5].

Bireylerin sağlı durumlarını gözlemlemek ve yaşam kaliteleri hakkında geri bildirim almak için günlük aktivitelerinin izlenmesi ve sınıflandırılması büyük önem taşımaktadır. Bu amaçla görsel ve sensör tabanlı olmak üzere iki farklı yaklaşım sunulmaktadır. Görsel tabanlı sistemler çok sayıda kameranın iç mekan ortamlara yerleştirilmesi sonucu veri alma imkanı verir. Ancak, bireyin yaşamını sürdürdügü her yerde kayıt yapmak mümkün olmadığı için kullanışlı değildir. Ayrıca yüksek bir maliyete sahiptir. Sensör tabanlı sistemler ise sahip olduğu küçük boyut, düşük maliyet, tekstil ürünleri üzerine entegre edilebilmesi ve küçük bir pille dış ortamlarda da kullanılabilme avantajlarıyla günümüzde daha sık kullanılmaktadır. Aktivite izlemede yaygın olarak kullanılan sensör modelleri ise ivme sensörü, jiroskop, kuvvet sensörü ve pedometredir.

Aktivite sınıflandırması için en önemli bileșen sınıflandırma algoritmalarıdır. Khan ve ark. [6], 6 farklı aktivite türünü ayırt edebilmek için yapay sinir ağlarını kullandıkları bir çalışma gerçekleştirmişlerdir. Bu amaçla ivme sensörü verilerini yapay sinir ağları algoritması için giriş parametresi olarak tanımlamışlardır. Lara ve ark. [7], mantıksal regresyon algoritması ile bireylerden alınan klinik ölçümleri ve ivme verilerinin kombinasyonunu kullanmışlardır. Bu doğrultuda yürüme, koşma, oturma, merdiven inme ve çıkma aktivitelerini \%95.7 doğrulukla ayırt edebilen bir sistem geliştirmişlerdir. Dadashi ve ark. [8], yüzücülerin kol ve bacaklarına ivme ve jiroskop sensörlerini yerleştirmiştir. Elde edilen veriler ile Hidden Markov modelini kullanarak 
kurbağalama yüzme aşamalarını otomatik olarak tespit etmişlerdir. Ballı ve ark. [9], akıllı saat üzerinde yer alan ivme ölçerler ile 9 farklı insan hareketine ait verileri toplamışlardır. Elde edilen veriler, 10 farklı makine öğrenmesi yöntemi ile sınıflandırma için kullanılmıș ve bu algoritmaların performansları karşılaştırılmıștır. Achkar ve ark. [10], ayak altına yerleștirdikleri 2 adet kuvvet sensöründen elde ettikleri veriler ile lineer regresyon modelini kullanarak sınıflandırma yapmak için en optimüm sensör konfigürasyonunu tespit etmişlerdir.

Bu çalışmada ise, vücudun farklı bölgelerine (omuz, göğüs, kol ve bacak) birer adet ivme sensörü yerleştirilmiştir. 4 farklı aktivite süresince eş zamanlı olarak 3-eksenli ham ivme verileri kaydedilmiştir. Bu aktiviteler yürüme, koşma, zıplama ve oturmakayağa kalkmaktan oluşmaktadır. Bu hareketler süresince elde edilen veriler ile yapay sinir ağları algoritmaları kullanılarak aktivite sınıflandırması yapılmıştır. Bu amaçla 3 farklı method uygulanmıştır. İlk olarak; her bir sensöre ait ham veriler yapay sinir ağları için farklı giriş parametreleri olarak kullanıldı ve aktivite sınıflandırma için en etkin vücut bölgesi tespit edildi. İkinci olarak; sınıflandırma için tespit edilen en etkin iki vücut bölgesindeki sensörlere ait ham verilerin kombinasyonu giriş parametresi olarak alınarak çoklu sayıda sensör kullanmanın sınıflandırmaya katkısı incelenmiştir. Son olarak ise vücudun 4 farklı bölgesinden elde edilen tüm ham veriler giriş parametresi olarak kullanılarak sınıflandırma yapılmıştır. Uygulanan metotlar neticesinde, iki veya daha fazla sensör verisinin kullanıldığı durumlarda yapay sinir ağlarının daha üstün bir performans gösterdiği tespit edilmiştir.

\section{Deneysel çalışmalar}

\subsection{Veri toplama sistemi ve işlemleri}

Veri toplama sistemi (anakart), aktiviteler süresince ivmesensörlerinden elde edilen ham verileri toplamak ve hafıza elemanına depolamak için tasarlanmıştır. Sistem bir mikrodenetleyici (Mbed NXP LPC1768), 4 adet ivme sensörü (MPU6050), bir hafıza kartı ve batarya biriminden oluşmaktadır. Mikrodenetleyici, tasarlanan sistemin ana bölümüdür ve I2C hat üzerinden ivme sensörleri ile haberleşerek 3-eksenli ivme verilerini toplamaktadır. Elde ettiği ham verileri, 'g-kuvveti' türünden ivme değerlerine dönüştürerek, SPI hat üzerinden hafıza kartına $100 \mathrm{~Hz}$ örnekleme hızı ile depolamaktadır. Tasarlanan sistemin blok diyagramı Şekil 1'de verilmiştir.

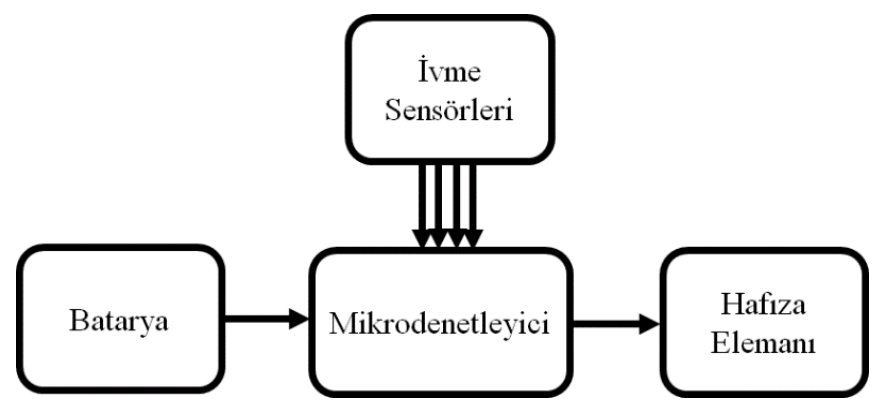

Şekil 1. Tasarlanan veri toplama sisteminin blok diyagramı.

Yapılan çalışmada, 4 adet ivme sensörü kullanılmıştır. Vücudun omuz, göğüs, kol ve bacak bölgelerine sensörleri yerleştirebilmek için çeşitli işlemler uygulanmıştır. İlk olarak, ivme sensörlerinin alt yüzeylerine, mevcut vida deliklerinden yararlanılarak 
kendinden yapışkanlı siyah cırt bant dikilmiştir. Dikilen cırt bantların boşta kalan kısımları ise silikon ile sensöre yapıştırılmıştır. Sonrasında ise cırt bantların karşılıkları giysinin ilgili bölgelerine dikilmiştir. Anakart ise kanguru cepli bir bel korsesi içerisine yerleştirilmiştir. Böylece, ana karta bağlı ivme sensörleri kablolar vasıtasıyla ilgili bölgelere götürülmüş ve cırt bantlar ile sabitlenmiştir. İvme sensörleri, ana kart ve yerleşim bölgeleri Şekil 2'de görülmektedir.

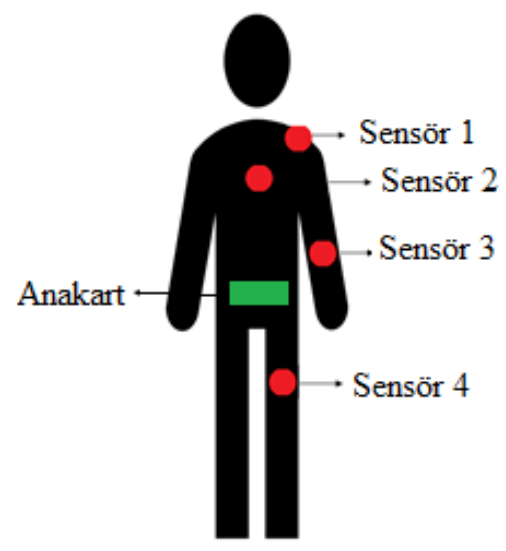

Şekil 2. Anakart ve sensörlerin yerleşim bölgeleri.

İvme sensörleri, üzerlerine düşen yerçekimi veya dinamik ivmeyi ölçebilen cihazlardır. Elde ettiği değerleri $\mathrm{m} / \mathrm{s} 2$ veya yerçekimi (g kuvveti) türünden ifade edilebilir. İvme sensörü performansını etkileyen en önemli unsurlar sensör kalibrasyonu ve gürültü problemidir. $\mathrm{Bu}$ amaçla; veri toplama işlemi öncesinde bireyin ayakta duruş pozisyonunda 30 saniye hareketsiz kalması istenerek kalibrasyon işlemi yapılmıştır. Veri toplama işlemi sonrası ise aktiviteler süresince meydana gelebilecek gürültü problemini ortadan kaldırmak için alçak geçiren filtre uygulandı.

Her bir bireyden 4 farklı aktiviteyi gerçekleştirilmesi istenmiştir. Bunlar; yürüme, koşma, zıplama ve oturma-ayağa kalkma hareketleridir. Veri toplama işlemi öncesinde, deneklerin benzer nitelikte hareketler gerçekleştirmeleri için 5 dakikalık bir eğitim verilmiş ve pratik yapmaları sağlanmıştır. Aktiviteyi gerçekleştirme hızları konusunda herhangi bir kısıtlama yapılmamış ve deneklere serbestlik verilmiştir. Bireylerden her bir aktivite için 1 dakika olmak üzere toplam 4 dakika boyunca veri toplanmıştır.

\subsection{Cok katmanlı algılayıcı yapay sinir ağları ve sınıflandırma}

Çok katmanlı algılayıcı (ÇKA) modeli, yapay sinir ağlarının önemli sınıflarından biridir. Çeşitli alanlarda çok sayıda uygulama için kullanımı mevcuttur. Ağ yapısı; bir giriş katmanı, bir ya da daha çok gizli katman ve bir çıkış katmanından oluşmaktadır. Her katman farklı sayıda nörona sahip olabilir ve komşu katmanların nöronları arasındaki bağlantılar ağırlık katsayıları ile sağlanır. İlk olarak, giriş verisi giriş katmanına verilir ve onun çıkışları gizli katmanı besler. Gizli katmanın çıkışı ise çıkış katmanına bağlanır ve son olarak ağın çıkışı, çıkış katmanından elde edilir. A $\breve{g}$ içerisindeki hesaplamalar gizli ve çıkış katmanlarında gerçekleşir. Ağg giriş ve çıkış verileri arasında lineer olmayan bir haritalama uygular ve bu geri yayılım algoritması üzerinden ağırlık katsayıları tarafından sağlanır [11].

Gizli ve çıkış katmalarındaki her bir nöron transfer fonksiyonu olarak adlandırılan özel bir matematiksel fonksiyon işlemi sunar. Bu fonksiyonlar, gelecek katmanlar için çıkış 
üretir. Geri yayılım algoritması için, sigmoid fonksiyon en yaygın kullanılan fonksiyonlardan biridir [12].

ÇKA sinir ağları ile sınıflandırma tahmini yapmak için elde edilen veriler eğitim ve test seti olarak ikiye ayrılmıştır. Her bir bireyden elde edilen verilerin \%60'1 eğitim veri seti olarak, \%40' 1 ise test veri seti olarak kullanılmıştır. Giriş verileri olarak, 4 parametre alınmıştır. Bunlar $\mathrm{x}$, y ve $\mathrm{z}$ terimleri cinsinden ivme verileri ile 3 eksenin oluşturduğu vektörün büyüklügüüür. Eğitim ve test işlemleri süresince yapay sinir ağlarının performansını arttırmak için giriş ve çıkış değerleri [-1,1] aralığına normalize edilmiştir. Tahmin işlemi sonrasında, normalize çıkış değerleri denormalize edilerek hedef değerler ile karşılaştırılmıştır.

Bu çalışmada, 6 farklı ÇKA sinir ağları modellemesi gerçekleştirilmiştir. Ağ 1 sadece omuz bölgesinden elde edilen verileri, Ağ 2 sadece kol bölgesinden elde edilen verileri, A $\breve{g} 3$ sadece bacak bölgesinden elde edilen verileri, Ağ 4 sadece göğüs bölgesinden elde edilen verileri giriş parametresi olarak kullanmaktadır. Çıkış parametreleri ise yürüme, koşma, zıplama ve oturma-ayağa kalkma hareketleri olarak alınmıştır. A $\breve{g} 1,2,3$ ve 4'ün performansları karşılaştırıldığında en iyi iki performansı veren vücut bölgelerine ait veriler Ağ 5'in giriş verisi olarak alındı. A $\breve{g} 6$ ise tüm verileri kapsamaktadır. Yapay sinir ağlarına örnek bir blok diyagram Şekil 3'de sunulmuştur.

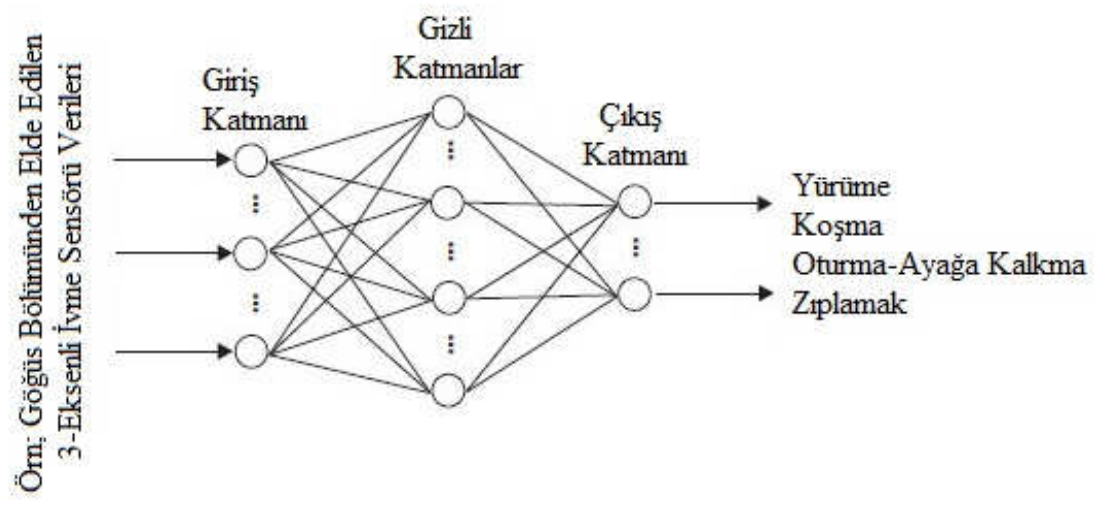

Şekil 3. Sınıflandırma için kullanılan ÇKA sinir ağlarının kullanımına ilişkin blok diyagram.

\section{Sonuçlar ve tartışma}

$\mathrm{Bu}$ çalışmada öncelikle tasarlanan anakart ile vücudun farklı bölgelerinden (gögüis, omuz, bacak ve kol) eş zamanlı olarak yürüme, koşma, zıplama, oturma-ayağa kalkma hareketleri için veriler toplanmıştır. Veri toplama işlemlerine, Dokuz Eylül Üniversitesi'nden 4'ü kadın ve 4'ü erkek olmak üzere toplam 8 gönüllü birey katılmıştır. Bireylerin yaşları 20-30, boyları 159-192 cm ve vücut ağırlıkları 50-100 kg aralığında değişkenlik göstermektedir. Herhangi bir sağlık problemleri yoktur. Her bir aktivite süresince vücudun farklı bölgelerinden elde edilen verilerin bir bölümü Şekil 4, 5, 6 ve 7'de gösterilmiştir. 

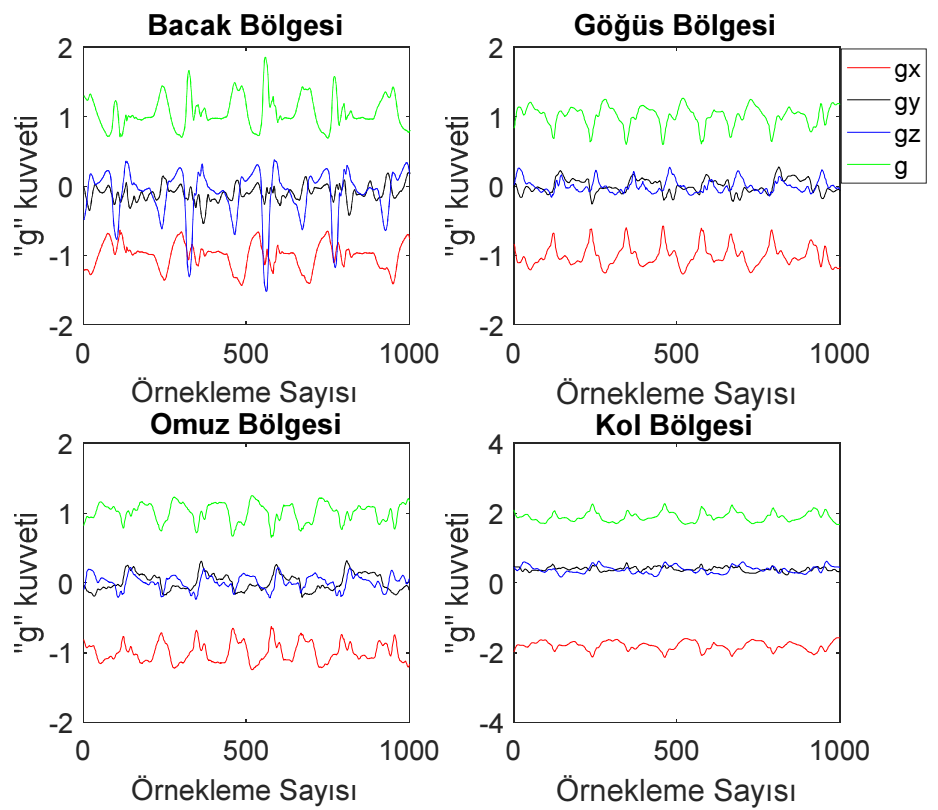

Şekil 4. Yürüme aktivitesi süresince vücudun farklı bölgelerinden elde edilen ivme sensörü verileri.
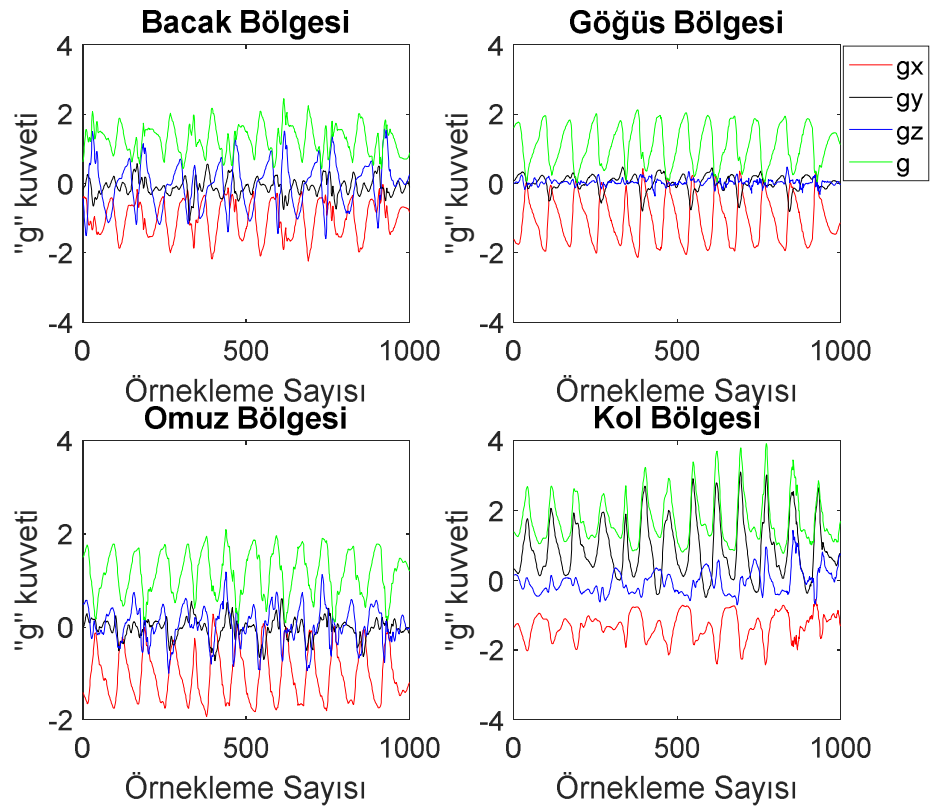

Şekil 5. Koşma aktivitesi süresince vücudun farklı bölgelerinden elde edilen ivme sensörü verileri. 

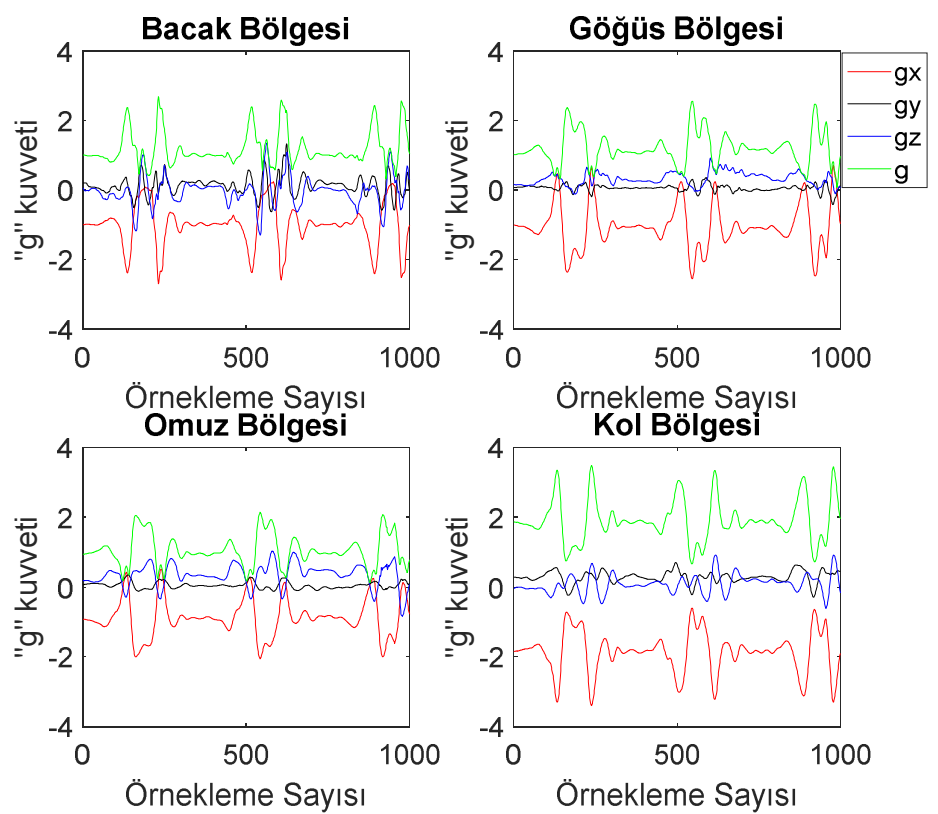

Şekil 6. Sıçrama aktivitesi süresince vücudun farklı bölgelerinden elde edilen ivme sensörü verileri.
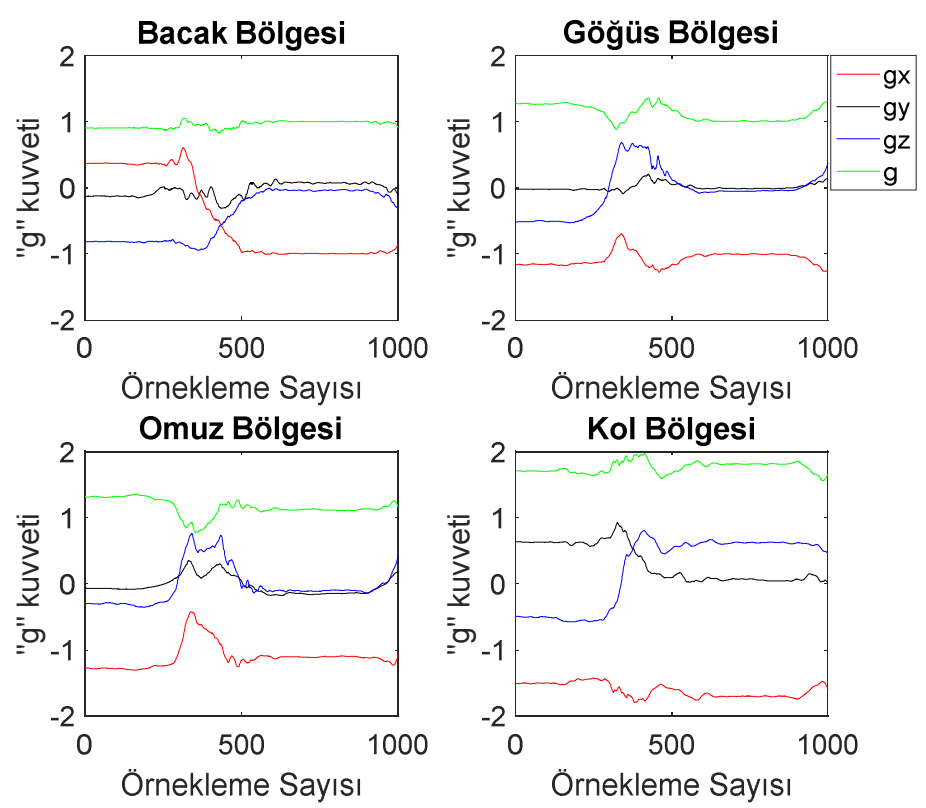

Şekil 7. Oturma-Ayağa kalkma aktivitesi süresince vücudun farklı bölgelerinden elde edilen ivme sensörü verileri.

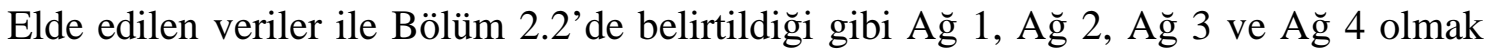
üzere 4 farklı ÇKA sinir ağı modelleri tasarlanmıştır. A $\breve{g} 1$ için omuz üzerinde yer alan sensöre ait veriler giriş, Ağ 2 için kol üzerinde yer alan sensöre ait veriler giriş, A $\breve{g} 3$ için bacak üzerinde yer alan sensöre ait veriler giriş, A $\breve{g} 4$ için ise gögüus üzerinde yer alan sensöre ait veriler giriş parametreleri olarak alınmıştır. Herbir ă̆ modeli için çıkış parametreleri ise yürüme, koşma, zıplama ve oturma-ayağa kalkma olarak belirlendi. 
Çeşitli nöron sayıları, gizli katman sayıları, farklı transfer fonksiyonları kullanılarak deneme-yanılma tekniği ile en iyi ağ performansları elde edilmiştir. Ağ performanslarının hem eğitim hem de test verileri için doğruluk oranları ' $\%$ ' türünden Tablo 1'de verilmiştir. Bu oranlar elde edilirken verilerin \%60'1 eğitim seti, \%40'1 ise test seti olarak alınmıştır.

Tablo 1. Bacak, göğüs, omuz ve kol bölgesi ivme verilerinin ayrı ayrı giriş parametresi olarak kullanıldığı durumda ÇKA sinir ağlarının sınıflandırma başarısı.

\begin{tabular}{|c|c|}
\hline A ̆̆ Numarası & Test Verisi \\
\hline $\mathrm{A} \breve{\mathrm{g}} 1$ & $\% 93.19$ \\
\hline $\mathrm{A} \breve{g} 2$ & $\% 89.91$ \\
\hline $\mathrm{A} \breve{g} 3$ & $\% 93.72$ \\
\hline A $\breve{g} 4$ & $\% 93.98$ \\
\hline
\end{tabular}

Veri toplama işlemleri sonunda omuz ve göğüs bölgesinden alınan verilerin benzerliği Şekil 4, 5, 6 ve 7'de görülmektedir. Yapay sinir ağları tarafından yapılan sınıflandırma tahminlerinde de bu benzerliğin sonuçlara yansıdığı doğrulanmıştır. Test sonuçlarını göz önüne alırsak göğüs bölümünden alınan veriler ile tasarlanan ağ modeli, omuz bölgesinden alınan veriler ile tasarlanan ă modeline göre \%0.8 civarında daha iyi sonuçlar göstermiştir. Bacak bölgesinden alınan veriler omuz bölgesinden alınan veriler ile gerçekleştirilen sınıflandırma işlemine göre daha iyi, göğüs bölgesinden alınan veriler ile gerçekleştirilen sınıflandırma işlemine göre ise daha kötü sonuç vermektedir. Bacak bölgesinde yer alan ivme sensörlerinin yer-tepkime kuvvetine bağlı olarak daha fazla gürültüye maruz kalmasının performansının gerilemesine sebep olmuş olabileceği düşünülmektedir. Kol bölgesinden alınan veriler giriş parametresi olarak alındığında ise en kötü ağ performansı elde edilmiştir.

En iyi performansı veren Ağ 3 ve Ağ 4 sinir ağları modellerinin giriş parametreleri birleştirilerek Ăg 5 adı verilen bir sinir ağı modeli üretilmiş ve performansı araştırılmıştır. Yapılan denemeler sonucunda Tablo 2'de yer alan sonuçlar elde edilmiştir.

Tablo 2. Bacak ve gögüs bölgesi verilerinin giriş parametresi olarak kullanıldığ1 durumda ÇKA sinir ağlarının sınıflandırma başarısı.

\begin{tabular}{|c|c|}
\hline Ağ Numaras1 & Test Verisi \\
\hline A $\breve{g} 5$ & $\% 98.9$ \\
\hline
\end{tabular}

A $\breve{g} 5$ sinir ağı modellemesi tek bir noktadan alınan sensör verileri yerine çoklu sayıda sensör ile farklı bölgelerden veri almanın sınıflandırma performansına olumlu katkıda bulunduğunu göstermiştir. Bu katkı \%5'in üzerindedir. Elde edilen bu sonuca bağlı olarak 4 farklı bölgeden elde edilen verilerin tamamı sinir ağları modeli giriş parametresi olarak kullanılmış ve Ağ 6 modeli oluşturulmuştur. Tablo 3'de ise Ağ 6'nın performansı gösterilmiştir. 
Tablo 3. Tüm verilerin giriş parametresi olarak kullanıldığı durumda ÇKA sinir ağlarının sınıflandırma başarısı.

\begin{tabular}{|c|c|}
\hline A ̆g Numaras1 & Test Verisi \\
\hline Ağ 6 & $\% 94.9$ \\
\hline
\end{tabular}

Farklı vücut bölgelerinden alınan tüm veriler giriş parametresi olarak kullanıldığında tek sensörlü ăg modellerine göre daha iyi bir performans alındığı ancak Ağ 5'e göre daha kötü bir performans alındığı görülmüştür. Elde edilen istatistikler çoklu sensör kullanmanın olumlu katkı sağladığını ancak etkin bölgeleri kullanmanın ağ performansı için önemli olduğunu göstermektedir.

\section{Tartışma ve sonuç}

Yapılan literatür araştırmasında, aktivite tanımlama için göğüs üzerine yerleştirilen bir ivme sensörü ile farklı kompleks algoritmaların ve çeşitli sinyal işleme tekniklerinin kullanıldığı değerlendirilmiştir. Gerçekleştirilen çalışmada ise aktivite tanımlamak için gögüs de dahil olmak üzere çeşitli vücut bölgeleri baz alınmış ve en efektif bölgeler tespit edilmiştir. Bunun sonucunda aktivite tanımlama için bacak ve omuz üzerinden elde edilen verilerin de gögüs üzerinden alınan veriler kadar değerli olduğu elde edilen pozitif sonuçlar doğrultusunda görülmüştür.

Çeşitli bölgelere ait verilerin birleştirilmesinin yapay sinir ağlarının performansına olumlu yönde katkı sağlamıştır. Ancak, her bölgeye ait tüm verilerin kullanılmasının her zaman pozitif katkı sağlamadığı da gözlemlenmiştir. Sonuç olarak, çoklu sayıda sensör verisinin olumlu katkı sağladığını ama her bölgeden toplanan verilerin bilinçsiz bir şekilde birlikte kullanılmasının performansı düşürdüğü kanaatine varılmıştır.

\section{Kaynakça}

[1] World Health Organization. Prevalence of insufficient physical activity. http://www.who.int/(Erişim Tarihi: 14.04.2018).

[2] Wahid, A. vd., Quantifying the Association Between Physical Activity and Cardiovascular Disease and Diabetes: A Systematic Review and Meta-Analysis, Journal of the American Heart Association, 5(9), (2016).

[3] Kyu, H.H. vd., Physical activity and risk of breast cancer, colon cancer, diabetes, ischemic heart disease, and ischemic stroke events: systematic review and doseresponse meta-analysis for the Global Burden of Disease Study, The BMJ, (2016).

[4] Brymer, E., Davids, K., Designing environments to enhance physical and psychological benefits of physical activity: a multidisciplinary perspective. Sports Medicine, 46(7), 925-926, (2016).

[5] Schuldhaus, D., Leutheuser, H., Eskofier, B.M., Classification of daily life activities by decision level fusion of inertial sensor data, In Proceedings of the 8th International Conference on Body Area Networks, ICST (Institute for Computer Sciences, Social-Informatics and Telecommunications Engineering, 77-82, (2013). 
[6] Khan, A.M., Lee, Y.K., Lee, S.Y., \& Kim, T.S., A triaxial accelerometer-based physical-activity recognition via augmented-signal features and a hierarchical recognizer, IEEE Transactions on Information Technology in Biomedicine, 14(5), 1166-1172, (2010).

[7] Lara, O.D., Pérez, A.J., Labrador, M.A., Posada, J.D., Centinela: A human activity recognition system based on acceleration and vital sign data, Pervasive and Mobile Computing, 8(5), 717-729, (2012).

[8] Dadashi, F., Arami, A., Crettenand, F., Millet, G.P., Komar, J., Seifert, L., Aminian, K., A hidden markov model of the breaststroke swimming temporal phases using wearable inertial measurement units, In Body Sensor Networks (BSN), 2013 IEEE International Conference on, 1-6, (2013).

[9] Balli, S., Sağbaş, E.A., Akıllı saat algılayıcıları ile insan hareketlerinin sınıflandırılması, Süleyman Demirel Üniversitesi Fen Bilimleri Enstitüsü Dergisi, 21(3), 1-11, (2017).

[10] El Achkar, C.M., Massé, F., Arami, A., Aminian, K., Physical activity recognition via minimal in-shoes force sensor configuration. In Proceedings of the 7th International Conference on Pervasive Computing Technologies for Healthcare. ICST (Institute for Computer Sciences, Social-Informatics and Telecommunications Engineering), 256-259 (2013).

[11] Hagan, M., Demuth, H.B., Jess, O.D. and Beale, M., Neural Network Design, , USA, (2014).

[12] Haykin, S., Neural Networks: A Comprehensive Foundation, Pearson Education, 9, India, (2005). 